\title{
A bioética de Francisco: elementos para a construção de uma bioética global cristã
}

\author{
The bioethics of Francis: elements for the building of a Christian global \\ bioethics
}

\author{
Anor Sganzerla* \\ Leocir Pessini* ${ }^{* *}$ \\ Diego Carlos Zanella***
}

\begin{abstract}
Resumo
Nos primeiros anos de seu pontificado, Papa Francisco fez pouco uso da palavra 'bioética'. Quando fez menção à palavra, empregou-a no sentido formal, para tratar de alguma comissão, e não para manifestar uma posição. Mas, a partir de 2018, Francisco assumiu uma posição bem definida em relação à bioética, afirmando que os nossos tempos precisam ampliar a visão tradicional da bioética para uma visão de bioética global, pois não é mais possível pensar a saúde, o bem-estar e a realização humanas de forma independente da saúde da totalidade da vida da biosfera. Essa bioética global, afirma Francisco, tem as suas bases na Laudato Si. Se o posicionamento escrito de Francisco sobre a bioética não ocorreu de forma imediata ao iniciar seu pontificado, a opção do pontífice de "começar" seu pontificado em Lampedusa, acolhendo migrantes e refugiados, deixou evidente qual seria o compromisso de sua Igreja. As duras palavras proferidas em Lampedusa, de que nos tornamos insensíveis aos gritos dos outros e que globalizamos a indiferença, tornando-nos incapazes de chorar pelo outro, deram o tom da sua missão. Nesse sentido, este artigo pretende investigar o pensamento bioético defendido pelo Papa Francisco a partir de documentos, encíclicas, homílias e cartas por ele escritas.
\end{abstract}

Palavras-chave: Papa Francisco. Bioética Global. Igreja Católica.

\begin{abstract}
In the early years of his pontificate, Pope Francis made little use of the word 'bioethics'. When he mentioned the word, he used it in a formal sense, to deal with some commission, and not to express a position. But, from 2018 on, Francisco took a well-defined position in relation to bioethics, stating that our times need to expand the traditional view of bioethics to a view of global bioethics, as it is no longer possible to think about health, well-being and human achievement independently of the health of the entire life of the biosphere. This global bioethics, says Francis, is based on Laudato Si. If Francis's written position on bioethics did not occur immediately when he started his pontificate, the pontiff's option to "start" his pontificate in Lampedusa, welcoming migrants and refugees, he made it clear what his Church's commitment would be. The harsh words spoken at Lampedusa, that we have become insensitive to the cries of others and that we have globalized indifference, making us unable to cry for the other, have set the tone for his mission. In this sense, this article intends to investigate the bioethical thought defended by Pope Francis from documents, encyclicals, homilies and letters he wrote.
\end{abstract}

Keywords: Pope Francis. Global Bioethics. Catholic Church.

Artigo submetido em 17 de fevereiro de 2019 e aprovado em 18 de agosto de 2020.

\footnotetext{
* Doutor em Filosofia. Professor da PUCPR. País de origem: Brasil. E-mail: anor.sganzerla@gmail.com

** In memoriam (1955-2019). Doutor em Teologia Moral. País de origem: Brasil.

*** Doutor em Filosofia. Professor da UFN. País de origem: Brasil. E-mail: diego.zanella@gmail.com
} 


\title{
Introdução
}

\begin{abstract}
A visão global da bioética, que vos apressastes a relançar no campo da ética social e do humanismo planetário, fortalecidos pela inspiração cristã, comprometer-se-á com mais seriedade e rigor a desativar a cumplicidade com o trabalho sujo da morte, apoiado pelo pecado. [...] Esta bioética não se moverá a partir da doença e da morte para decidir o sentido da vida e definir o valor da pessoa. Ao contrário, mover-se-á a partir da profunda convicção da irrevogável dignidade da pessoa humana, assim como Deus a ama, dignidade de cada pessoa, em cada fase e condição da sua existência, na busca das formas do amor e do cuidado que devem ser dedicados à sua vulnerabilidade e fragilidade [...]. Portanto, em primeiro lugar, esta bioética global será uma modalidade específica para desenvolver a perspectiva da ecologia integral que é própria da Encíclica Laudato Si [...]. Em segundo lugar, numa visão holística da pessoa, trata-se de estruturar com clareza cada vez maior todas as ligações e as diferenças concretas nas quais habita a condição humana universal e que nos envolvem a partir do nosso corpo. (FRANCISCO, 2018a, p. 2).
\end{abstract}

Em sua história, a Igreja Católica sempre pretendeu ser uma voz afirmativa, precisa, corajosa e misericordiosa a favor da dignidade da vida humana. Frente aos temas, que hoje são classificados como do universo da bioética e que são tratados nos documentos pontifícios, a exemplo do aborto, da eutanásia, do prolongamento da vida, da reprodução assistida, do transplante de órgãos, entre outros, a Igreja Católica sempre manteve uma posição firme em defesa da inviolabilidade e da sacralidade da vida humana. E com o Papa Francisco não foi diferente. A defesa da dignidade, da inviolabilidade e da sacralidade da vida humana assume lugar de destaque em sua missão.

Mas o tempo, as necessidades humanas e ambientais do pontificado de Francisco diferem dos pontificados anteriores. A época de Francisco é marcada por profundas e rápidas transformações em todas as esferas, sobretudo, devido ao forte impacto que a revolução tecnocientífica tem sobre a natureza humana, a vida da biosfera, a prevalência dos interesses econômicos e políticos das grandes nações e corporações, sobre os valores éticos e morais, o bem comum, a diversidade cultural e religiosa e a voz dos injustiçados. Francisco precisou adequar a Igreja às novas necessidades.

Se a defesa da dignidade e da inviolabilidade da vida humana sempre ganharam destaque na doutrina da Igreja Católica, o Papa Francisco alerta-nos 
de que é preciso ampliar os horizontes, visto que não é mais possível pensar na defesa da vida humana, sua dignidade e inviolabilidade, independente da defesa da totalidade da vida na biosfera, o que o pontífice chamou de Casa Comum. Nesse sentido, diante das ameaças à natureza e ao ser humano promovidas pelo ideal de progresso, pelo modelo de produção e de consumo, que se fundamentam no lucro imediato, o pontífice propõe uma "virada profética”, ou seja, uma renovada visão social, econômica, (geo)política, ecológica, cultural e teológica da Igreja Católica em defesa de uma ecologia integral. (FRANCISCO, 2015, p. 70-71).

Essa renovação, proposta pelo pontífice na encíclica Laudato Si, trouxe consequências para toda a humanidade, mesmo para aqueles que não comungam da mesma fé. Nesse sentido, a exortação feita pelo Papa mostra que os graves problemas globais de nossos tempos, não tem uma resposta técnica, ou mesmo uma resposta para cada problema, e por isso é preciso buscar um novo paradigma, não mais voltado para a ideia de progresso e de lucro, pensando unicamente nos interesses humanos mais imediatos, mas sim, com o cuidado para com a Casa Comum.

O posicionamento de Francisco em relação aos inúmeros problemas emergentes de nossos tempos, que ameaçam a dignidade da vida humana e da vida futura da biosfera, está em sintonia com as preocupações de muitos estudiosos, pesquisadores, militantes e simpatizantes que se reúnem em torno das questões do universo da bioética. Este artigo quer investigar qual é o pensamento bioético defendido pelo pontífice, a partir de documentos, encíclicas, homílias e cartas do Papa Francisco.

\section{Em defesa e promoção de uma bioética global}

Nos primeiros anos de seu pontificado, Francisco pouco se utilizou da palavra 'bioética' em seus documentos e encíclicas, e nas raras vezes que o termo foi usado, o sentido empregado era muito mais para informar a existência de um órgão ou comissão, como ocorreu no Discurso do Papa Francisco à Comissão Italiana de Bioética (2016), no qual o pontífice agradece ao trabalho 
prestado pela Comissão Nacional de Bioética, do que usar da bioética como uma instrumento em auxílio aos problemas globais de nossos tempos.

A carta encíclica Laudato Si (2015), que problematiza questões do universo da bioética, ao tratar principalmente da vulnerabilidade do ser humano e da natureza frente o poder desmedido do mundo globalizado, que age sem levar em conta os valores humanos e da natureza, é um bom exemplo para mostrar o pouco espaço que a bioética tinha no pensamento de Francisco, visto que, embora a encíclica trate, em sua essência, de questões de bioética, em nenhum momento a palavra 'bioética' foi usada na encíclica. As razões para tanto não são tão evidentes.

Mas, a partir de 2018, no Discurso do Papa Francisco aos participantes na assembleia da Pontifícia Academia para a Vida, o termo 'bioética' entrou de modo oficial nos documentos do Papa Francisco, e, de modo bastante claro, afirmando que a "bioética global será uma modalidade específica para desenvolver a perspectiva da ecologia integral que é própria da encíclica Laudato Si”. (FRANCISCO, 2018a, p. 2).

Ao fazer referência à bioética global, Francisco (2018a) afirma que ela se faz necessária para alargar as fronteiras da bioética tradicional, pois precisamos de uma bioética que seja capaz de defender a sacralidade da vida embrional com a mesma paixão que deverá ser capaz de defender a sacralidade da vida dos pobres que já nasceram e clamam por justiça social. Trata-se, pois, de defender a vida em suas múltiplas dimensões, na inserção com o ambiente e na ecologia humana. Afirma Francisco que "a bioética chama-nos à sabedoria de um discernimento profundo e objetivo do valor da vida pessoal e comunitária" (FRANCISCO, 2018a, p. 3), que deve ser assegurado mesmo quando as condições forem de extrema dificuldade.

O Papa (2018a) inicia seu discurso afirmando que a sabedoria que deve inspirar o comportamento humano em "relação à 'ecologia humana' é chamada a considerar a qualidade ética e espiritual da vida em todas as suas fases" (FRANCISCO, 2018a, p. 1), porque a vida não pode ser concebida somente em seu aspecto físico, pois existe também a vida eterna, a vida em família, a vida em 
comunidade, a vida humana partilhada com as outras formas de vida em nossa casa comum. Além disso, existe a vida saudável, mas também a vida frágil, doente, marginalizada, carregada dos mistérios mais profundos e sagrados.

Os estudos em relação à vida feitos em laboratórios são importantes e imprescindíveis, porque eles revelam as dimensões físicas, químicas e mecânicas da vida, afirma o pontífice. No entanto, é preciso ir além da dimensão técnica, pois a vida precisa ser compreendida em uma dimensão integrada, ampla e profunda. Nesse sentido, é necessário dar "atenção à vida propriamente humana, que irrompe no cenário do mundo com o prodígio da palavra e do pensamento, dos afetos e do espírito" (FRANCISCO, 2018a, p. 1). E essa perspectiva, conclui o pontífice, não tem recebido a atenção e o espaço necessários, dentro da política e da cultura das ciências da natureza.

A prática do abandono de parte da população mundial, como as crianças, os pobres e os idosos representa o “trabalho 'sujo' da morte” (FRANCISCO, 2018a, p. 2), pois o outro é excluído do nosso horizonte, da nossa comunidade, o que faz com que nos tornemos cegos para a vida do outro e sua dinâmica, agindo como verdadeiros Narcisos, acrescentou o pontífice. Assim sendo, a visão global de bioética proposta por Francisco não busca tratar do sentido da vida e do valor da pessoa humana a partir da doença e da morte, mas ao contrário "mover-se-á a partir da profunda convicção da irrevogável dignidade da pessoa humana” (FRANCISCO, 2018a, p. 2), presente em cada fase e condição de sua existência, de uma vida que é frágil e vulnerável, e, que precisa de cuidado e de um ambiente natural e saudável para poder se desenvolver.

Como uma forma específica de desenvolver a ecologia integral (FRANCISCO, 2018a, p. 2), a bioética global de Francisco requer que se proteja a casa comum e se busque um desenvolvimento humano e da biosfera de modo sustentável, com o reconhecimento da interdependência entre as realidades.

No Discurso do Papa Francisco aos participantes na assembleia da Pontifícia Academia para a Vida, o pontífice usa da encíclica Laudato Si como pano de fundo em defesa da bioética global na busca pela ecologia integral. Afirma o pontífice que é preciso saber identificar a 
relação íntima entre os pobres e a fragilidade do planeta, a convicção de que tudo está estreitamente interligado no mundo, a crítica do novo paradigma e das formas de poder que derivam da tecnologia, o convite a procurar outras maneiras de entender a economia e o progresso, o valor próprio de cada criatura, o sentido humano da ecologia, a necessidade de debates sinceros e honestos, a grave responsabilidade da política internacional e local, a cultura do descarte e a proposta de um novo estilo de vida. (FRANCISCO, 2018a, p. 2).

Se o atual modelo de globalização tende a aumentar e aprofundar as desigualdades, mostrando que as condições de miséria, de pobreza e de violação da dignidade humana são condições locais e naturais, é preciso estar atento para reagir frente a essa concepção e mostrar que a qualidade de vida das pessoas e sua dignidade estão diretamente ligadas às condições globais, sejam elas sociais, econômicas, culturais e ambientais, afirma o pontífice.

Essa ecologia integral requer também, segundo o pontífice, com que se pense em uma visão holística da pessoa, reconhecendo que o nosso corpo nos coloca "em relação direta com o meio ambiente e com os outros seres vivos" (FRANCISCO, 2018a, p. 2), e que aprender a cuidar, a respeitar e a compreender o significado do corpo é essencial para a verdadeira compreensão da ecologia humana. E acrescenta que é preciso respeitar o corpo em suas diferenças fundamentais: "do homem e da mulher, da paternidade e da maternidade, a fraternidade, a sexualidade, a doença, o envelhecimento, a violência, a guerra, de modo a tornar-se capaz de reconhecer a si mesmo no encontro com o diferente". (FRANCISCO, 2018a, p. 2).

Para alcançar uma ecologia humana integral, com uma compreensão harmoniosa e total da condição humana, o tema da ética da vida humana, afirma o pontífice, precisa encontrar seu adequado lugar na antropologia social, ou seja, é preciso, recolocar a vida em sua centralidade e saber interrogar-se sobre o destino último da existência, de modo a "restituir a dignidade e sentido ao mistério das suas afeições mais profundas e mais sagradas”. (FRANCISCO, 2018a, p. 2).

Os interesses do mundo globalizado de nossos tempos, tem dificultado colocar a vida na centralidade da existência. Por isso, a importância da bioética global, como a sabedoria capaz de repensar a vida do ser humano, da 
humanidade e de seu ambiente. Afirma o pontífice que "a perspectiva da bioética global, com a sua visão ampla e a atenção ao impacto do meio ambiente sobre a vida e a saúde, constitui uma oportunidade notável para aprofundar a nova aliança do Evangelho e da criação”. (FRANCISCO, 2019a, p. 6).

Trata-se de repensar a função, a responsabilidade e o papel do ser humano na biosfera, visto que somente com a utilização da lei e do conhecimento técnico, não é possível garantir as condições de proteção à dignidade da vida humana e da biosfera. Por isso, afirma o Pontífice, "a bioética chama-nos à sabedoria de um discernimento profundo e objetivo do valor da vida pessoal e comunitária, que deve ser preservado e promovido até nas condições mais difíceis”. (FRANCISCO, 2018a, p. 3).

\section{A bioética de Francisco no contexto geral da bioética}

Aqueles que estão mais familiarizados com o campo da bioética reconhecerão que a perspectiva de Francisco de buscar uma bioética global, de promover o diálogo entre os diferentes saberes e culturas, da necessidade de romper com o modelo antropocentrista de pensamento, de exigir com que os ideias do progresso sejam orientados por princípios éticos e morais em vista ao bem-comum, faz com que a bioética de Francisco esteja em sintonia com a bioética global proposta Van Rensselaer Potter, considerado um dos "pais da bioética”.

Em suas obras Bioética: Ponte para o Futuro (1971) e Bioética Global (1988), ${ }^{1}$ Potter mostra toda a sua preocupação com a sobrevivência da vida humana e da biosfera no futuro, a necessidade de uma perspectiva cósmico ecológica, o esforço interdisciplinar de construir uma ponte para unir o bios (vida) com o ethos (ética), ou seja, as ciências humanas com as ciências do ambiente e da saúde, a ciência e a técnica com a ética (ZANELLA, 2018). Essa ponte proposta por Potter aplica-se para diferentes contextos: i) ponte entre o presente e o futuro (as ações humanas devem ser pensadas a longo prazo); ii)

\footnotetext{
${ }^{1}$ Vale a pena destacar que as obras de Van Rensselaer Potter, Bioética: Ponte para o Futuro e Bioética Global, encontram-se traduzidas ao português. Há também uma terceira obra, que foi organizada a partir de textos inéditos de Potter e de seus principais comentadores, intitulada Van Rensselaer Potter: um bioeticista original. As três obras juntas formam o que denominamos na literatura bioética brasileira de a trilogia potteriana (POTTER, 2016; POTTER, 2018; PESSINI; SGANZERLA; ZANELLA, 2018).
} 
ponte entre ciência e valores (o desenvolvimento da ciência e da técnica tem que ocorrer em sintonia com a ética); iii) ponte entre natureza e cultura (o conhecimento não pode comprometer a natureza e a dignidade humana); e, iv) ponte entre o ser humano e a natureza (os interesses humanos não podem se opor aos interesses da natureza).

A bioética global é o segundo conceito evolutivo de Potter após o conceito inicial de bioética ponte. É definida como "sobrevivência aceitável, sustentável a longo prazo". Potter (2018) elenca cinco objetivos para a bioética global: i) saúde humana mundial: melhoria do nível de saúde no mundo com a prevenção de doenças e desenvolvimento de programas de saúde pública; ii) respeito mundial pelos direitos das mulheres; iii) políticas que evitem o perigo da superpopulação; iv) uma economia direcionada para o "bem comum", comunidade, meio ambiente e para um futuro sustentável; e v) a busca de uma nova ética. Ampliar a ética profissional para além das especialidades médicas, que leve em conta o bem comum e os diretos sociais. Trata-se de uma bioética global para uma vida sustentável. Para Potter (2018), a bioética global é marcada por cinco virtudes, a saber: humildade, hospitalidade, competência interdisciplinar, competência intercultural e compaixão.

Ao afirmar que a saúde humana depende diretamente da saúde ambiental e que o adoecimento de uma das partes promoverá o prejuízo a outra parte, e que a ação humana sobre a natureza se compara às células cancerígenas agindo sobre o corpo humano, Potter, assim como Francisco, reconhece que não é mais possível pensar a qualidade de vida humana, a sua saúde, sem levar em conta a ciência ecológica e os problemas da sociedade em escala global. No Discurso do Papa Francisco à Comissão Italiana de Bioética (2016) o pontífice afirma que "a bioética nasceu para confrontar, através de um esforço crítico, as razões e as condições que a pessoa humana exige, face ao progresso das ciências e das tecnologias biológicas e médicas" (FRANCISCO, 2016, p. 1), que movidas pela ideia da rapidez e do novo correm o risco de agir unicamente tendo como referência a ideia de utilidade e de proveito. 
A bioética global de Francisco exige, portanto, com que se mudem as condutas, os paradigmas, tanto na esfera individual quanto coletiva, em vista à sobrevivência humana, respeitando a pluralidade cultural e ética e a rica diversidade do planeta. $\mathrm{O}$ atual estilo de vida clama por um conhecimento ecológico e por uma moralidade que possa assegurar não somente os interesses atuais, mas também das futuras gerações.

Alerta-nos Francisco de que em épocas de grandes crises, como a dos nossos tempos, é preciso ter ainda mais claro quais são os valores que acreditamos e propomos, para poder lutar em sua defesa. É na busca desse compromisso que Francisco conduz a sua Igreja.

Utilizando-se da Carta da Terra $^{2}$ que nos convida à uma nova consciência universal e a um novo início, não mais destrutivo, mas fundamentado no cuidado pela vida, Francisco afirma que o "nosso tempo seja lembrado pelo despertar de uma nova reverência face a vida, pelo compromisso firme de alcançar a sustentabilidade, a intensificação da luta pela justiça e pela paz, e a alegre celebração da vida". (FRANCISCO, 2015, p. 64).

A Carta da Terra é uma declaração de princípios fundamentais para a construção de uma sociedade global, justa, sustentável e pacífica no século XXI. O documento procura inspirar em todos os povos um novo sentido de interdependência global e de responsabilidade compartilhada pelo bem-estar de toda a humanidade. É uma expressão de esperança e um chamado a contribuir para a criação de uma sociedade global em um contexto crítico na história. A visão ética do documento é inclusiva e reconhece que a proteção ambiental, os direitos humanos, o desenvolvimento humano equitativo e a paz são interdependentes e inseparáveis.

No preâmbulo, o anúncio da gravidade do momento histórico que estamos vivendo: "Estamos num momento crítico da história da Terra, numa

\footnotetext{
2 Em 1987, a Comissão Mundial das Nações Unidas para o Meio Ambiente e Desenvolvimento fez um chamado para a criação de uma nova carta que estabelecesse os princípios fundamentais para o chamado desenvolvimento sustentável. A redação desse documento começou no Rio de Janeiro, em 1992, na chamada Cúpula da Terra, mas "fez parte dos assuntos não concluídos". Em 1997, a Comissão da Carta da Terra iniciou uma série de consultas. A Carta da Terra é o resultado de uma série de debates interculturais, realizados em todo o mundo por mais de uma década. A versão final da Carta foi aprovada na reunião celebrada na sede da Unesco, em Paris, em março de 2000. Disponível em: https://cartadaterrainternacional.org.
} 
época em que a humanidade tem de escolher o seu futuro. À medida que o mundo se torna cada vez mais interdependente e frágil, o futuro encerra, ao mesmo tempo, grandes perigos e grandes promessas". (CARTA DA TERRA, 2000).

E, olhando para o futuro, "[...] devemos conjugar forças para gerar uma sociedade global sustentável, baseada no respeito pela natureza, nos direitos humanos universais, na justiça econômica e numa cultura da paz. Para alcançar esse propósito, é imperativo que nós, os povos da Terra, declaremos nossa responsabilidade uns para os outros, para com a grande comunidade da vida, e para com as gerações futuras". (CARTA DA TERRA, 2000).

\section{Em defesa e promoção de uma ecologia integral}

A encíclica Laudato Si: sobre o cuidado da casa comum (2015) é o documento, que fundamenta a bioética global de Francisco, mesmo que, conforme dissemos acima, sem fazer uso do termo bioética. Ao tratar da bioética global (no Discurso do Papa Francisco aos participantes na assembleia da Pontificia Academia para a Vida), o pontífice utiliza de trechos da encíclica Laudato Si, na qual defende a perspectiva da ecologia integral, evidenciando que tudo no mundo está "estreitamente interligado" (FRANCISCO, 2015, p. 6), e que, desse modo, não é mais possível pensar de forma "fragmentada e isolada" (FRANCISCO, 2015, p. 44), pois tudo está intimamente relacionado, de modo que "os problemas atuais requerem um olhar que leve em conta todos os aspectos da crise mundial”. (FRANCISCO, 2015, p. 43).

Os seres humanos, afirma a Laudato Si, são parte e fruto da natureza, e desse modo, "ficamos impedidos de considerar a natureza como algo separado de nós, ou como uma mera moldura da nossa vida. Estamos incluídos nela, somos parte dela e compenetramo-nos" (FRANCISCO, 2015, p. 44). Por sermos parte da natureza, isso significa que temos um compromisso com ela. Se a modernidade compreendeu a natureza como indiferente, permitindo, desse modo, uma ação devastadora sobre ela, é preciso promover uma conversão humana e ecológica, de modo a compreendermos a natureza como casa comum. E para isso, precisamos construir um novo paradigma, afirma o pontífice. 
A qualidade de vida humana não se dá de forma independente da qualidade de vida do ambiente. Em ambientes deteriorados, afirma Francisco, o aumento da violência e da criminalidade se tornam mais expressivos. $\mathrm{O}$ mesmo acontece com o estado de saúde das instituições de uma sociedade, pois seu modo de ser e agir tem consequências no próprio ambiente e na qualidade da vida humana. Afirma o pontífice: "toda lesão da solidariedade e da amizade cívica provoca danos ambientais”. (FRANCISCO, 2015, p. 45).

Quando parte da natureza sofre um processo de contaminação, e, ao buscarmos os motivos pelos quais tal contaminação ocorreu, deveríamos "fazer uma análise do funcionamento da sociedade, da sua economia, do seu comportamento, das suas maneiras de entender a realidade" (FRANCISCO, 2015, p. 44). E acrescenta o pontífice que "os ambientes onde vivemos influem sobre a nossa maneira de ver a vida, sentir e agir”. (FRANCISCO, 2015, p. 47).

Assim sendo, as alternativas aos problemas ambientais e sociais de nossos tempos, não podem ser encontradas independentes do contexto global, pois os sistemas naturais estão interligados aos problemas sociais. Para mostrar essa interdependência, o pontífice afirma: "não há duas crises separadas: uma ambiental e outra social; mas uma complexa crise socioambiental" (FRANCISCO, 2015, p. 44), o que faz com que o cuidado com a natureza ocorra de modo simultâneo com o combate à pobreza e a defesa da dignidade humana, principalmente dos mais pobres e vulneráveis. Esse é o sentido da bioética global defendida por Francisco.

Há um modo "desordenado de conceber a vida e a ação do ser humano" (FRANCISCO, 2015, p. 32) no mundo, fundamentado no ideal de progresso, de desenvolvimento, de produção e de consumo. Esse ideal, pretende impor-se e justificar-se independente da "responsabilidade, dos valores, e da consciência" (FRANCISCO, 2015, p. 3), e com isso, sua prática se efetiva independente das consequências negativas que possa trazer ao futuro da biosfera e das futuras gerações. Um verdadeiro progresso não pode ser pensado de modo "independente da melhoria global da qualidade de vida humana". (FRANCISCO, 2015, p. 47). 
A desfiguração e a exploração da natureza promovida pelo ser humano traz como consequência a desumanização do próprio ser humano. Afirma o pontífice:

quando os seres humanos destroem a biodiversidade na criação de Deus; quando os seres humanos comprometem a integridade da terra e contribuem para a mudança climática, desnudando a terra de suas florestas naturais ou destruindo as suas zonas húmidas; quando os seres humanos contaminam as águas, o solo, o ar... tudo isso é pecado. Porque um crime contra a natureza é um crime contra nós mesmos e um pecado contra Deus. (FRANCISCO, 2015, p. 3).

E, sobretudo, os cristãos, afirma Francisco, que são chamados a compreender o mundo como "sacramento de comunhão, como forma de partilhar com Deus e com o próximo numa escala global” (FRANCISCO, 2015, p. 3), pois o divino e o humano se encontram no menor detalhe da natureza, devem comprometer-se no combate das realidades promotoras da desfiguração humana e da natureza, denunciar os efeitos deletérios da tecnocracia, superar o antropocentrismo, promover a conversão ecológica, dar seu testemunho, em uma "mudança do ser humano" (FRANCISCO, 2015, p. 3) em vista a uma ecologia integral.

Embora a ciência e a técnica tenham a pretensão de representar o "principal recurso para interpretar a existência” (FRANCISCO, 2015, p. 35), como se fosse possível buscar uma resposta personalizada para cada problema, Francisco afirma que esse modo de pensar busca "esconder os problemas verdadeiros e mais profundos do sistema mundial" (FRANCISCO, 2015, p. 35), com a grande possiblidade de "tomar em consideração sintomas que não correspondem às problemáticas mais profundas” (FRANCISCO, 2015, p. 46), pois não há um "remédio técnico para cada problema” (FRANCISCO, 2015, p. 36). E, as consequências se tornam ainda mais nefastas, quando a técnica e seus produtos pretendem convencer a sociedade que sua ação é neutra. Conclui a esse respeito o pontífice que a “[...] técnica não é neutra, e seus produtos [...] são opções sobre o tipo de vida social que se pretende desenvolver". (FRANCISCO, 2015, p. 34). 
O pontífice reconhece a urgente necessidade de interligar as várias ecologias (ambiental, econômica, social, cultural, da vida cotidiana) em vista de uma ecologia integral. Se o atual modelo de desenvolvimento promoveu uma “deterioração ética, cultural [...] e ecológica” (FRANCISCO, 2015, p. 51), é preciso colocar "alguns limites razoáveis e até retroceder [...] antes que seja tarde [...] por isso, chegou a hora de aceitar como certo decréscimo do consumo em algumas partes do mundo" (FRANCISCO, 2015, p. 60), de modo que se torne possível crescer de modo saudável e sustentável nas sociedades mais pobres, pois estes são os primeiros a sofrer as consequências desse modelo de exploração sem limites. (PESSINI; SGANZERLA, 2017). 3

A integração das diferentes ecologias leva-nos ao resgate do princípio do bem comum, com o respeito "pela pessoa humana [...] seus direitos fundamentais e inalienáveis orientados para o desenvolvimento integral” (FRANCISCO, 2015, p. 49). Para tanto, é preciso resgatar a "consciência de uma origem comum, de uma recíproca pertença e de um futuro partilhado por todos". (FRANCISCO, 2015, p. 63).

Devemos buscar um consenso mundial, não sob a ótica dos atuais interesses econômicos e políticos das grandes nações, que visam interesses pessoais, mas sim em torno de "programar uma agricultura sustentável e diversificada, desenvolver formas de energia renováveis e pouco poluidoras, fomentar uma maior eficiência energética, promover uma gestão mais adequada dos recursos florestais e marinhos, garantir a todos o acesso a água potável”. (FRANCISCO, 2015, p. 51).

\section{Em defesa e promoção do diálogo e da reflexão interdisciplinar}

A ecologia integral pressupõe a integração dos diferentes saberes, pois se os problemas estão interligados globalmente, não há respostas isoladas das

\footnotetext{
${ }^{3}$ Leo Pessini é um dos grandes mestres da bioética brasileira, mas também internacional. Seu entusiasmo pelo mundo da bioética é reconhecido por todos, sendo inclusive reconhecido como um bioeticista da esperança (SGANZERLA, 2019). O trabalho que fez pela promoção da bioética no Brasil é impar e exemplar. Nos últimos anos, nós três vínhamos trabalhando em um projeto de tradução e divulgação do pensamento de Van Renssenlaer Potter (1911-2001) em língua portuguesa. Dessa parceria de trabalho resultaram a tradução da obra seminal de Potter, Bioética: Ponte para o Futuro (POTTER, 2016), Van Rensselaer Potter: Um Bioeticista Original (PESSINI; SGANZERLA; ZANELLA, 2018), e, mais recentemente, A Bioética de V. R. Potter: 50 anos depois (SGANZERLA; ZANELLA, 2020). Além desses trabalhos, este artigo também faz parte desse projeto, pois a bioética global proposta pelo Papa Francisco está muito próxima do pensamento bioético de Potter. Com isso, registramos aqui nossa admiração pelo querido amigo e incentivador Leo Pessini, que muito cedo nos deixou.
} 
ciências que possam ser eficazes. É preciso que ocorra um verdadeiro diálogo entre as culturas humanista-literária e teológica com a científica, de modo a incluir as dimensões humanas, sociais e ambientais. Caso contrário, até mesmo se usarmos os melhores dispositivos, com as mais modernas tecnologias, mas sem levarmos em conta as "metas e valores, e uma compreensão humanista e rica de significado" (FRANCISCO, 2015, p. 56) da complexa condição humana, os possíveis êxitos econômicos e políticos, poderão estar em oposição aos interesses do bem comum.

A urgente necessidade da promoção do diálogo entre os saberes e as diferentes culturas ocupa todo o capítulo V da encíclica Laudato Si. Este diálogo proposto pelo pontífice aparece como uma linha de orientação e de ação por ele defendida. Trata-se do diálogo em relação as questões do meio ambiente na política internacional, na formação de novas políticas nacionais e locais que possam estar a serviço da pessoa humana, do bem comum e do respeito à natureza, na transparência nos processos decisórios, nas decisões econômicas e políticas em vista à plenitude humana, e no diálogo das religiões com as ciências.

O diálogo proposto pelo pontífice que apela para os diferentes saberes busca na construção de uma "visão mais integral e integradora" (FRANCISCO, 2015, p. 45) do ser humano, com as questões sociais e ambientais. Trata-se da necessidade imperiosa de priorizar o humanismo, visto que a análise dos "problemas ambientais é inseparável da análise dos contextos humanos, familiares, laboratoriais, urbanos, e de relação de cada pessoa consigo mesma, que gera um modo específico de se relacionar com os outros e com o meio ambiente". (FRANCISCO, 2015, p. 45).

A falta desse diálogo entre as ciências e entre as diferentes culturas leva a um empobrecimento de ambas as partes, e a Igreja Católica, como instituição global defensora das diferenças e da prática dialógica deve ter esse propósito em sua missão. Trata-se de buscar um "debate honesto e transparente, para que as necessidades particulares ou as ideologias não lesem o bem comum”. (FRANCISCO, 2015, p. 58). 
Um grande passo em vista ao diálogo entre as diferentes culturas ocorreu por conta da viagem apostólica do Papa Francisco aos Emirados Árabes Unidos, no ano de 2019, no qual se sentiu a necessidade de elaborar um documento em conjunto, entre Al-Azhar e a Igreja Católica, que pudesse servir de guia "para as novas gerações rumo à cultura do respeito mútuo, na compreensão da grande graça divina que torna irmãos todos os seres humanos”. (FRANCISCO, 2019a, p. 1).

O documento intitulado A fraternidade humana em prol da paz mundial e da convivência comum estabelece como grandes princípios norteadores entre as duas civilizações: "a cultura do diálogo como caminho; a colaboração comum como conduta; o conhecimento mútuo como método e critério" (FRANCISCO, 2019a, p. 1). O relacionamento entre oriente e ocidente, afirma o documento, tornou-se uma necessidade mútua indiscutível, de modo que ambas as culturas possam se engrandecer, e vencer os males de seu tempo. Da parte do ocidente, a cultura oriental poderia ser um remédio para os males causados pelas doenças espirituais e religiosas devido ao materialismo, e da parte da civilização oriental, a cultura ocidental poderia contribuir para "salvar-se da fragilidade, da divisão, do conflito e do declínio científico, técnico e cultural” (FRANCISCO, 2019a, p. 1). O documento ainda destaca que é fundamental que se preste atenção e se respeite todas as diferenças existentes (religiosas, culturais, históricas...), bem como que se consolide "os direitos humanos gerais e comuns" (FRANCISCO, 2019a, p. 1) de modo a garantir a dignidade a todos.

A interdisciplinaridade e a transparência devem ocorrer, afirma o pontífice, de modo "independente de qualquer pressão econômica ou política" (FRANCISCO, 2015, p. 57). Nesse sentido, o estudo sobre o impacto ambiental de projetos produtivos e políticos, por exemplo, não deve ocorrer somente depois que o projeto for implementado, mas sim, desde a sua concepção, de modo a poder avaliar as consequências em relação às condições de trabalho, e, de seus possíveis efeitos sobre a saúde física do trabalhador, o impacto na economia local, no meio ambiente, na segurança, entre outras esferas. É preciso, conclui Francisco, que os "vários atores sociais, que possam trazer diferentes perspectivas, soluções e alternativas" (FRANCISCO, 2015, p. 57) tenham voz 
ativa, e que o princípio da precaução tenha lugar de destaque para que se possa proteger os mais fracos e vulneráveis.

Na Carta do Papa Francisco ao Presidente da Pontifícia Academia para a Vida por ocasião do XXV aniversário de fundação (11 de fevereiro de 1994 11 de fevereiro de 2019), intitulada Humana communitas, o pontífice se utiliza de uma concepção4 de bioética apresentada pelo Papa João Paulo II, na encíclica Evangelium Vitae, para mostrar a necessidade da promoção da "reflexão e diálogo - entre crentes e não crentes, assim como entre crentes de diversas religiões - sobre problemas éticos, inclusive fundamentais, que interessam a vida do homem" (FRANCISCO, 2019b, p. 1), pois a crise antropológica e socioambiental é de dimensão global5. Com o ritmo cada vez mais crescente de inovação tecnológica em uma sociedade globalizada, "multiplicam-se as interações entre culturas, religiões e saberes diversos, bem como entre as múltiplas dimensões da família humana e da casa comum onde vivem" (FRANCISCO, 2019b, p. 2), por isso, torna-se urgente analisar as consequências dessas mudanças tecnológicas e seus impactos sobre a natureza humana e a vida da biosfera. Nesse sentido, vivemos um grande paradoxo, afirma o pontífice, porque é justamente no momento histórico de maior conquista econômica e tecnológica que temos as "divisões (humanas, sociais e ambientais) mais agressivas e aos nossos piores pesadelos”. (FRANCISCO, 2019b, p. 3).

Ao tratar da reforma das faculdades e universidades eclesiásticas, o pontífice, no documento intitulado Veritatis Gaudium (2017a), afirma que é necessária uma verdadeira "hermenêutica evangélica para compreender melhor

\footnotetext{
${ }^{4}$ João Paulo II (1995), na encíclica Evangelium Vitae (n. 27), afirma: "Particularmente significativo é o despertar da reflexão ética acerca da vida: a aparição e o desenvolvimento cada vez maior da bioética favoreceu a reflexão e o diálogo - entre crentes e não crentes, como também entre crentes de diversas religiões - sobre problemas éticos, mesmo fundamentais, que dizem respeito à vida do homem". (JOÃO PAULO, 1995).

${ }^{5}$ Também é importante destacar a concepção de bioética do Papa Bento XVI (2009), na encíclica Caritas in Veritatis (n. 74): “Hoje, um campo primário e crucial da luta cultural entre o absolutismo da técnica e a responsabilidade moral do homem é o da bioética, onde se joga radicalmente a própria possibilidade de um desenvolvimento humano integral. Trata-se de um âmbito delicadíssimo e decisivo, onde irrompe, com dramática intensidade, a questão fundamental de saber se o homem se produziu por si mesmo ou depende de Deus. As descobertas científicas neste campo e as possibilidades de intervenção técnica parecem tão avançadas que impõem a escolha entre estas duas concepções: a da razão aberta à transcendência ou a da razão fechada na imanência. Está-se perante uma opção decisiva. No entanto a concepção racional da tecnologia centrada sobre si mesma apresenta-se como irracional, porque implica uma decidida rejeição do sentido e do valor. Não é por acaso que a posição fechada à transcendência se defronta com a dificuldade de pensar como tenha sido possível do nada ter brotado o ser e do acaso ter nascido a inteligência. Face a estes dramáticos problemas, razão e fé ajudam-se mutuamente; e só conjuntamente salvarão o homem: fascinada pela pura tecnologia, a razão sem a fé está destinada a perder-se na ilusão da própria omnipotência, enquanto a fé sem a razão corre o risco do alheamento da vida concreta das pessoas". (PAPA BENTO XVI, 2009).
} 
a vida, o mundo, os homens; não de uma síntese, mas de uma atmosfera espiritual de investigação e certeza fundamentada nas verdades da razão e da fé” (FRANCISCO, 2017a, p. 5), mas para tanto é preciso estar com o pensamento aberto, incompleto e em desenvolvimento. E para mostrar essa abertura de modo a ultrapassar a ideia de síntese, Francisco recorre ao que ele chama de lei descrita por São Vicente de Lerins: “annis consolidetur, dilatetur tempore, sublimetur aetate” (FRANCISCO, 2017a, p. 5), ou seja, "não é possível conservar a doutrina sem fazê-la progredir”.

Ao tratar da renovação dos estudos eclesiásticos, Francisco, na Veritatis Gaudium, não se limita a orientar a formação dos estudos dos presbíteros, ou mesmo das pessoas de vida consagrada ou de leigos comprometidos, mas sim, de toda comunidade acadêmica e científica, de crentes e não crentes, pois tornou-se urgente "uma renovação acadêmica e de investigação científica em vista a um novo paradigma [...] uma corajosa revolução cultural” (FRANCISCO, 2017a, p. 5) para mudar o modelo de desenvolvimento global e de redefinição do progresso.

Essa renovação proposta pelo Papa, na encíclica Veritatis Gaudium, estabelece quatro critérios de inspiração: i) a contemplação: como critério primário e permanente, a introdução espiritual, intelectual e existencial no coração do querigma; ii) o diálogo: trata-se de um diálogo sem reservas, não como simplesmente uma tática, mas como uma exigência intrínseca para fazer a experiência, e para promover uma cultura do encontro "entre todas as culturas autênticas e vitais" (FRANCISCO, 2017a, p. 6); um diálogo entre cristãos com outras convicções religiosas e humanistas, e ao mesmo tempo manter o cuidado de cultivar os "contatos com os estudiosos de outros ramos do saber, quer se trate de crentes quer de não crentes, procurando entender e saber interpretar as suas afirmações, bem como ajuizar sobre elas à luz da verdade revelada" (FRANCISCO, 2017a, p. 6); iii) a interdisciplinaridade $e \quad a$ transdisciplinaridade: não se quer apenas a busca de diferentes teorias no entendimento de tal realidade, mas sim de uma forte transdisciplinaridade, de modo que a pessoa possa "situar-se a si mesma e à própria ciência, a que chega, por assim dizer, a partir de um cume, depois de ter tido uma visão global de 
todo o saber" (FRANCISCO, 2017a, p. 8); e, iv) a criação de redes: diante dos problemas e das necessidades globais, é preciso criar redes com os diferentes países, instituições, tradições religiosas e culturais, em vista de alcançar alternativas que possam beneficiar a todos.

Destaca Francisco, na Laudato Si, que "desde meados do século passado e superando muitas dificuldades, foi-se consolidando a tendência de conceber o planeta como pátria e a humanidade como povo que habita uma casa comum" (FRANCISCO, 2015, p. 51). O reconhecimento de que o mundo é interdependente faz com que não apenas reconheçamos que as consequências do atual estilo de vida, de consumo e de produção afetem a todos, e principalmente os mais pobres, mas principalmente na busca de soluções dentro de uma perspectiva global. Conclui Francisco que a "interdependência obriga-nos a pensar num único mundo, num projeto comum”. (FRANCISCO, 2015, p. 51).

\section{$5 \mathrm{Em}$ defesa e promoção do futuro da humanidade}

Se historicamente o tema do futuro da humanidade ganhou pouca atenção da parte dos estudiosos e pesquisadores, das diferentes áreas do conhecimento, porque compreendia-se que o futuro era dado como certo, e desse modo, não haveria porque preocupar-se, as múltiplas possibilidades de interferência sobre a vida em geral, e, a natureza humana em particular, apresentadas pela tecnociência, faz do tema o futuro da humanidade, um dos debates mais imprescindíveis em plena era da civilização tecnológica. As certezas apresentadas pelas diversas tradições religiosas e filosóficas na história em relação à pergunta quem é o homem? O que o torna singular e único nesse mundo? deixam lugar para as muitas dúvidas em relação a identidade do ser humano.

Preocupado com o futuro da humanidade e com a necessidade de repensar uma nova antropologia, o Papa Francisco, em seu Discurso aos participantes da plenária do Pontifício Conselho para a Cultura (2017) afirma que antes de mais nada "devemos expressar a nossa gratidão aos homens e às mulheres de ciência pelos seus esforços e pelo seu compromisso a favor da 
humanidade" (FRANCISCO, 2017b, p. 1). No entanto, embora a tecnociência tenha contribuído fortemente para aprofundar os conhecimentos da biosfera e da natureza humana, ela sozinha, afirma o pontífice, "não é suficiente para dar todas as respostas” (FRANCISCO, 2017b, p. 1) que são necessárias. É preciso resgatar a sabedoria das tradições religiosas do saber popular, da literatura, das artes, da filosofia, da teologia, que promovem o acesso ao mistério da existência humana. A urgência em resgatar o humanismo, como seus múltiplos saberes, em vista de uma visão integral e integradora, ganhou todo o destaque na carta encíclica Laudato Si. (FRANCISCO, 2015, p. 45).

Em seu Discurso aos Participantes da plenária do Pontifício Conselho para a Cultura, Francisco destaca três pontos em relação ao tema do futuro da humanidade: i) os avanços da medicina e da genética são muitos e seus resultados permitem conhecer o ser humano em sua interioridade, de modo a intervir na cura de certas doenças consideradas até então incuráveis. Por outro lado, juntamente com essa conquista temos também o perigo de podermos "programar" a formação de seres humanos segundo critérios por nós estabelecidos, de modo a melhorar as capacidades físicas e cognitivas superando aspectos considerados indesejáveis da condição humana. Essas possibilidades exigem com que se reflita com toda atenção sobre o que constitui o especificamente humano; ii) as conquistas da neurociência sobre $\mathrm{o}$ funcionamento do nosso cérebro exige com que as realidades como a consciência de si, a liberdade, a própria alma, entre outras, sejam postas em discussão; e, iii) os progressos das máquinas autônomas, que já são parte da nossa realidade, e que misturam e se integram como se fossem "naturais" ao humano.

Esses extraordinários avanços científicos no campo da genética, das neurociências, da inteligência artificial e na capacidade de modificar a natureza humana (PESSINI, 2017, p. 301), têm influenciado no modo de conceber a saúde humana, o bem-estar físico e psicológico, no exercício da responsabilidade, no livre-arbítrio, entre outros. Mas, é na dimensão antropológica que se vislumbra os maiores impactos e consequências, pois "os 
grandes princípios e os conceitos essenciais da antropologia” (FRANCISCO, 2017b, p. 1) que norteavam essas questões até hoje são postos a prova.

A Igreja, afirma Francisco, para anunciar o Evangelho aos homens de hoje, e fazer-se crer, não pode dispensar-se dessa reflexão em busca de uma valoração moral, de uma revisão das categorias antropológicas e éticas, e do diálogo em torno do significado do ser humano e da própria concepção de vida humana. Se a investigação científica se estruturou de modo globalizado, é preciso, no entanto, reconhecer, a existência das múltiplas tradições culturais e éticas, que precisam ser respeitadas nas suas diferenças, e não unificadas.

Não há como negar os grandes avanços nos campos da tecnociência, da medicina, na indústria dos nossos tempos, principalmente nos países desenvolvidos. No entanto, juntamente com essas grandes conquistas, "se verifica uma deterioração ética que condiciona a atividade internacional [...] e um inaceitável silêncio" (FRANCISCO, 2019a, p. 1), o que nos leva a perder o sentido de responsabilidade pelo outro.

Os avanços da tecnociência nos colocam frente "a grandes e graves interrogações que devemos enfrentar" (FRANCISCO, 2017b, p. 1), visto que, muito do que era conhecido apenas na literatura e em filmes de ficção científica tornou-se realidade. Por isso, não podemos permitir que a tecnociência decida por si só a respeito do futuro da humanidade. É preciso dialogar em torno dos critérios e dos valores que devem guiar a prática científica. Afirma Francisco que "a medicina e a economia, a tecnologia e a política que são elaboradas no centro da moderna cidade do homem, devem permanecer expostas também e sobretudo ao juízo que é pronunciado pelas periferias da terra”. (FRANCISCO, 2019b, p. 1).

E a Igreja que acompanha os homens e "deseja colocar a pessoa humana e as questões que lhe dizem respeito, no centro das próprias reflexões" (FRANCISCO, 2017a, p. 1), não pode omitir-se dessa participação. É da essência do cristianismo a capacidade de se renovar, mantendo-se fiel “[...] à sua identidade e ao tesouro de verdade que recebeu de Jesus Cristo [...] de repensar 
e de reformular o diálogo com as novas situações históricas, deixando desabrochar assim a sua eterna novidade”. (FRANCISCO, 2015, p. 38).

Para orientar esse diálogo, o Papa Francisco, no Discurso aos Participantes da plenária do Pontifício Conselho para a Cultura lembra de alguns princípios defendidos pela Igreja: i) a centralidade da pessoa humana considerada sempre como fim e nunca como meio; ii) o destino universal dos bens, ou seja, o progresso cientifico e tecnológico deve estar em benefício de toda a humanidade, e, para tanto, as grandes decisões e orientações da pesquisa científica e dos investimentos, "devem ser tomadas pelo conjunto da sociedade e não ditadas apenas pelas regras do mercado ou do interesse de poucos" (FRANCISCO, 2017b, p. 1), porque a verdadeira medida do progresso é o bem comum. Assim sendo, tornou-se inconcebível para o próprio bem da humanidade, pensar que a tecnociência possa avançar unicamente seguindo os desejos e as vontades do mercado, e não sob valores morais e éticos pensados coletivamente. Afirma o pontífice que devemos "civilizar o mercado, na perspectiva de uma ética amiga do homem e do seu ambiente”. (FRANCISCO, 2017c, p. 1).

\section{Em defesa e promoção dos mais vulneráveis}

No pontificado de Francisco, o tema migrantes e refugiados tem recebido uma atenção especial, pois eles representam, segundo o pontífice, um "sinal dos tempos" FRANCISCO, 2018b, p. 1). A visita a Lampedusa (2013), uma ilha italiana que tem sido um importante ponto de chegada de migrantes e refugiados, principalmente oriundos da África e do Oriente Médio, foi o lugar escolhido por Francisco para "iniciar" o seu pontificado, não no sentido cronológico, mas de importância e de significado. Com a visita a Lampedusa, Francisco mostrou os claros objetivos da Igreja que ele dirige, e seu compromisso na promoção do evangelho social.

Na homília realizada em Lampedusa, Francisco (2013) assegurou que "senti o dever de vir aqui hoje para rezar, para cumprir um gesto de solidariedade, mas também para despertar as nossas consciências a fim de que não se repita o que aconteceu” (FRANCISCO, 2013, p. 1). Para Juan Carlos 
Scannone (2018), em seu ensaio A ética social do Papa Francisco: o evangelho da misericórdia segundo o espírito do discernimento, "[t]udo isso confirma que o fio de ouro da misericórdia tece a ética social do Papa Francisco, em relação a colocar os pobres no centro do caminho tanto da Igreja quanto da humanidade global, e ao seu modo de proceder para discernir a ação salvadora de Cristo e do Espírito - as duas mãos do Pai - na história e na ação histórica". (SCANNONE, 2018, p. 16).

Em outro momento de sua homilia, Francisco afirma que a cultura do bem-estar de nossos tempos, "torna-nos insensíveis aos gritos dos outros [...] e leva-nos à globalização da indiferença" (FRANCISCO, 2013, p. 1), ou seja, passamos a entender que o sofrimento do outro não nos diz respeito e que nada possamos fazer. Ao se referir às vítimas dos naufrágios ocorridos naqueles dias, Francisco questionou:

quem de nós chorou por este fato e por fatos como este? Quem chorou pela morte destes irmãos e irmãs? Quem chorou por estas pessoas que vinham de barco? Pelas mães jovens que traziam os seus filhos? Por estes homens cujo desejo era conseguir qualquer coisa para sustentar as próprias famílias? (FRANCISCO, 2013, p. 1).

Após ter proferido esses duros questionamentos, Francisco concluiu que a globalização da indiferença fez com que "perdêssemos a capacidade de chorar" (FRANCISCO, 2013, p. 1) pelo outro que sofre e que nada tem. Pelas pessoas que deixam suas terras em busca de uma vida melhor para suas famílias, mas encontram a morte pelo caminho. E encerra sua homília, pedindo ao Senhor que nos dê a graça de sermos capazes de chorar pela indiferença e pela crueldade que há mundo. A linguagem do testemunho é uma de suas grandes marcas.

Na Mensagem do Papa Francisco para o dia mundial do migrante e refugiado, o pontífice afirma: "repetidas vezes, durante estes meus primeiros anos de pontificado, expressei especial preocupação pela triste situação de tantos migrantes e refugiados que fogem das guerras, das perseguições, dos desastres naturais e da pobreza" (FRANCISCO, 2018b, p. 1). Tal situação tornou-se tão grave, que quando institui o novo Dicastério para o serviço do desenvolvimento humano integral, "quis que houvesse nele uma Secção 
especial [...] sob a minha guia direta” (FRANCISCO, 2018b, p. 1) para tratar dessas vítimas.

Todos nós, afirma o pontífice, "crentes e homens e mulheres de boa vontade” (FRANCISCO, 2018b, p. 1), somos desafiados a mudar de mentalidade, de modo a não reconhecer no migrante e refugiado apenas um indivíduo, um número estatístico que representa uma ameaça, mas sim uma "pessoa, com sua história, cultura, sentimentos e anseios [...] que tem direitos fundamentais e dignidade" (FRANCISCO, 2018c, p. 1) que precisa ser protegida e defendida. Sua experiência de vida e seus valores muito podem contribuir para enriquecer as sociedades, por isso, o desafio está em "sair ao encontro do outro, para acolhê-lo, conhecê-lo e reconhecê-lo" (FRANCISCO, 2018c, p. 1), de modo a superar o extremo estado de vulnerabilidade por eles vivido, pois "se sentem sós e isolados em todas as etapas” (FRANCISCO, 2018c, p.1) deste drama, ou seja, ficam abandonados desde a saída de seu país de origem, até o seu destino.

Afirma o Papa que todos os migrantes e refugiados esperam uma única coisa de nós, isto é, que sejamos capazes de destruir o muro da "cumplicidade cômoda e silenciosa" (FRANCISCO, 2018c, p.1) e que façamos despertar a compaixão e a dedicação. E da parte dos Estados envolvidos, o Papa pede para que seja possível adotar um pacto mundial, um acordo, capaz de assegurar "responsabilidade e humanidade, assistência e proteção". (FRANCISCO, 2018d, p. 1).

Em 14 de janeiro de 2018, no Dia mundial dos migrantes e refugiados, o Papa Francisco celebrou uma missa na intenção de todos os migrantes e refugiados, e fazendo uso de uma passagem do Evangelho de Mateus (25, 35-43) em que afirma que "todo estranho que bate à nossa porta é uma oportunidade para conhecer Jesus Cristo, que se identifica com o estrangeiro que foi aceito ou rejeitado em todas as épocas" (FRANCISCO, 2018b, p. 1). Para o pontífice, é na acolhida ao migrante e ao refugiado, é no encontro com o outro que seremos capazes de conhecer Jesus Cristo. E acrescenta que as comunidades locais que acolhem, conhecem e reconhecem, que respeitam a diversidade, os potenciais, as esperanças, os medos, as vulnerabilidades daqueles que chegaram, tornam vivo o Evangelho. 
Em busca de respostas concretas à realidade dos migrantes e refugiados, Francisco indica quatro grandes atitudes a serem praticadas: acolher, proteger, promover e integrar. O processo de i) acolher significa oferecer "possibilidades mais amplas de entrada segura e legal nos países de destino"; "incrementar e simplificar a concessão de vistos humanitários”; oferecer abertura de "corredores humanitários para os refugiados mais vulneráveis"; garantir "vistos temporários especiais [...] em países vizinhos"; oferecer um primeiro "alojamento adequado e decente"; e esforçar-se em buscar outras alternativas em "nome da dignidade fundamental de cada pessoa". (FRANCISCO, 2018b, p. 1).

A atitude de ii) proteger significa buscar ações em "defesa dos direitos e da dignidade dos migrantes e refugiados, independentemente da sua situação migratória” (FRANCISCO, 2018b, p. 1). Esta proteção deve começar em sua própria pátria garantindo as informações necessárias e posteriormente deve continuar no país de destino, assegurando-lhes uma "assistência consular adequada, o direito de manter sempre consigo os documentos de identidade pessoal, um acesso equitativo à justiça, a possibilidade de abrir contas bancárias pessoais e a garantia de uma subsistência vital mínima"; "a possibilidade de trabalhar e o acesso aos meios de telecomunicação"; "a garantia do acesso regular à instrução primária e secundária" e a possibilidade de "continuar seus estudos na maioridade"; superar a questão de ser um apátrida através da "legislação sobre a cidadania que esteja em conformidade com os princípios fundamentais do direito internacional”. (FRANCISCO, 2018b, p. 1).

A atitude de iii) promover significa permitir com que os migrantes e refugiados tenham as condições para realizar-se enquanto pessoas em todas as dimensões. Destaca o pontífice a dimensão religiosa, ou seja, o direito do estrangeiro à "liberdade de profissão e prática da religião" (FRANCISCO, 2018b, p. 1), como também o reconhecimento, a certificação e a validação de suas competências.

Por fim, a atitude de iv) integrar. Insiste Francisco na necessidade de favorecer a cultura do encontro "multiplicando as oportunidades de intercâmbio cultural, documentando e difundindo as 'boas práticas' de integração e 
desenvolvendo programas tendentes a preparar as comunidades locais para os processos de integração”. (FRANCISCO, 2018b, p. 1).

Ao encerrar a mensagem, Francisco deixa claro que a Igreja reafirma seu compromisso na realização das iniciativas acima mencionadas, mas conclama a comunidade política e a comunidade civil para exercer suas responsabilidades. Trata-se também de um desafio à comunidade internacional, pois é preciso tomar consciência dessa condição, para que sejam possíveis "respostas concretas e dignas a este desafio humanitário" (FRANCISCO, 2018c, p. 1). Torna-se urgente, destaca Francisco, contrastar a cultura de querer descartar todos aqueles sujeitos considerados vulneráveis, em vista da competição e da defesa do ideal de liberdade e de progresso.

\section{Considerações finais}

Ao afirmar que precisamos de uma bioética global que possa ir além da bioética tradicional, Francisco dá o tom de seu pensamento bioético. Embora os temas refletidos pela bioética tradicional sejam de extrema importância para os nossos tempos, pois a sociedade passou a conceber a morte como o fim e a vida apenas como um bem de consumo, que veio a este mundo por acaso e tudo vai acabar em nada, o que "autorizaria" as pessoas a fecharem-se em si mesmas, excluindo o outro de seu horizonte. Francisco recorre à bioética global para ampliar os horizontes da bioética e ser sinal de esperança em defesa da totalidade da vida humana e da biosfera, principalmente dos mais pobres e vulneráveis que tem sua dignidade ameaçada desde o seu nascimento até a morte.

Desse modo, a visão de bioética global de Francisco está voltada ao campo da ética social e do humanismo planetário, comprometida em lutar contra o pecado que tem gerado a destruição da natureza e do ser humano. Essa bioética global, realçada por Francisco, deverá tratar do sentido da vida, do valor da pessoa humana, da defesa da vida da biosfera, da dignidade da vida em todas as fases, pois a vida é frágil e vulnerável, e precisa ser acolhida com amor e cuidado. Esse modo de agir, conforme Francisco, permitirá desenvolver a ecologia integral e nos reconhecermos pertencentes à casa comum, pois o bem- 
estar e a saúde humana dependem diretamente da harmonia da vida da biosfera.

A bioética global de Francisco exige sabedoria e discernimento profundos porque nos tornamos capazes de grandes realizações. Reconhece Francisco que somente a jurisdição será incapaz de orientar esse processo. Precisamos refletir em relação a antropologia, a ética e ao bem comum, de modo que essas possiblidades de melhoramento do ser humano e da própria natureza, apresentadas pelo ideal do progresso, não se constituam em verdadeiras ameaças.

A bioética global de Francisco quer dar visibilidade aos sujeitos vulneráveis que vivem em sociedades livres. Nesse sentido, o pontífice faz da bioética global um instrumento de denúncia, pois desvela o que está sendo escondido e ao mesmo tempo conclama a todos, cristãos e não cristãos, a sair da zona de conformo para construir uma nova sociedade mais justa, solidária e fraterna, com um novo paradigma, não mais guiado pelos interesses do mercado, mas sim, em vista do bem comum.

Os subtítulos dessa reflexão trazem a expressão "em defesa e promoção" e seu propósito é mostrar qual é o compromisso da bioética global proposta por Francisco, ou seja, ao mesmo tempo que pretende ser a defesa e proteção das realidades e das pessoas mais vulneráveis, a bioética global também cumpre o propósito de ser uma voz de promoção da dignidade da totalidade da vida da biosfera.

\section{REFERÊNCIAS}

BENTO XVI, Papa. Carta Encíclica Caritas in Veritate: sobre o desenvolvimento humano integral na caridade e na verdade. 29 de junho de 2009. Disponível em: http://www.vatican.va/content/benedict-xvi/pt/encyclicals/documents/hf_benxvi_enc_20090629_caritas-in-veritate.html. Acesso em: 17 nov. 2020.

CARTA DA TERRA. 200o?. Disponível em: https://earthcharter.org/wpcontent/uploads/2020/03/echarter_portuguese.pdf?x79755. Acesso em: 30 out. 2020. 
FRANCISCO, Papa. Angelus. 17 de junho de 2018d. Disponível em: http://www.vatican.va/content/francesco/pt/angelus/2018/documents/papafrancesco_angelus_20180617.html. Acesso em: 17 nov. 2020.

FRANCISCO, Papa. Carta do Papa Francisco ao Presidente da Pontifícia Academia para a Vida por ocasião do XXV aniversário de fundação (11 de fevereiro de 1994 - 11 de fevereiro de 2019): Humana communitas ( comunidade humana). 2019b. Disponível em: http://www.vatican.va/content/francesco/pt/letters/2019/documents/papafrancesco_20190106_lettera-accademia-vita.html. Acesso em: 17 nov. 2020.

FRANCISCO, Papa. Carta Encíclica Laudato Si: sobre o cuidado da casa comum. 2015. Disponível em:

http://www.vatican.va/content/francesco/pt/encyclicals/documents/papafrancesco_20150524_enciclica-laudato-si.html. Acesso em: 17 nov. 2020.

FRANCISCO, Papa. Constituição apostólica Veritatis Gaudium: sobre as universidades e as faculdades eclesiásticas. 8 de dezembro de 2017a. Disponível em:http://www.vatican.va/content/francesco/pt/apost_constitutions/documents/pap a-francesco_costituzione-ap_20171208_veritatis-gaudium.html. Acesso em: 17 nov. 2020.

FRANCISCO, Papa. Discurso do Papa Francisco à Comissão Italiana de Bioética. 28 Janeiro de 2016. Disponível em: http://www.vatican.va/content/francesco/pt/speeches/2016/january/documents/pap a-francesco_20160128_comitato-nazionale-bioetica.html. Acesso em: 17 nov. 2020.

FRANCISCO, Papa. Discurso do Papa Francisco aos participantes na assembleia da Pontifícia Academia para a Vida. 25 de junho de 2018a. Disponível em:

http://www.vatican.va/content/francesco/pt/speeches/2018/june/documents/papafrancesco_20180625_accademia-provita.html. Acesso em: 17 nov. 2020.

FRANCISCO, Papa. Discurso do Papa Francisco aos participantes na plenária do Pontifício Conselho para a Cultura. 18 de novembro de 2017b. Disponível em: http://www.vatican.va/content/francesco/pt/speeches/2017/november/documents/p apa-francesco_20171118_plenaria-cultura.html. Acesso em: 17 nov. 2020.

FRANCISCO, Papa. Discurso do Papa Francisco aos participantes no encontro promovido pela Pontifícia Academia das Ciências Sociais. 20 de outubro de 2017c. Disponível em:

http://www.vatican.va/content/francesco/pt/speeches/2017/october/documents/papa -francesco_20171020_incontro-pass.html. Acesso em: 17 nov. 2020.

FRANCISCO, Papa. Mensagem do Papa Francisco para o dia mundial do migrante e do refugiado 2018: "acolher, proteger, promover e integrar os migrantes e os refugiados". 14 de fevereiro de $2018 \mathrm{~b}$. Disponível em: http://www.vatican.va/content/francesco/pt/messages/migration/documents/papafrancesco_20170815_world-migrants-day-2018.html. Acesso em: 17 nov. 2020.

FRANCISCO, Papa. Mensagem do Papa Francisco por ocasião do diálogo Santa Sé-México sobre a migração internacional. 14 de junho de 2018c. Disponível em: http://www.vatican.va/content/francesco/pt/messages/pontmessages/2018/documents/papa-francesco_20180614_messaggio-migrazione.html. Acesso em: 17 nov. 2020. 
FRANCISCO, Papa. Viagem a Lampedusa (Itália). Santa Missa pelas vítimas dos naufrágios. Homilia do Santo Padre Francisco. 8 de julho de 2013. Disponível em:

http://www.vatican.va/content/francesco/pt/homilies/2013/documents/papafrancesco_20130708_omelia-lampedusa.html. Acesso em: 17 nov. 2020.

FRANCISCO, Papa. Viagem apostólica do Papa Francisco aos Emirados Árabes Unidos: documento sobre a fraternidade humana em prol da paz mundial e da convivência comum. 3-5 de fevereiro de 2019a. Disponível em:

http://www.vatican.va/content/francesco/pt/travels/2019/outside/documents/papafrancesco_20190204_documento-fratellanza-umana.html. Acesso em: 17 nov. 2020.

JOÃO PAULO II, Papa. Carta Encíclica Evangelium Vitae: sobre o valor e a inviolabilidade da vida humana. 25 de março de 1995. Disponível em: http://www.vatican.va/content/john-paul-ii/pt/encyclicals/documents/hf_jpii_enc_25031995_evangelium-vitae.html. Acesso em: 17 nov. 2020.

PESSINI, L. Bioética, humanismo e pós-humanismo no século XXI: em busca de um novo ser humano? Revista Eclesiástica Brasileira, Rio de Janeiro?, v. 77, n. 306, p. 301-347, 2017. Disponível em:

https://revistaeclesiasticabrasileira.itf.edu.br/reb/article/view/83. Acesso em: 17 nov. 2020.

PESSINI, L.; SGANZERLA, A.; ZANELLA, D. C. (orgs.). Van Rensselaer Potter: um bioeticista original. São Paulo: Loyola, 2018.

PESSINI, L; SGANZERLA, A. Crise ambiental e crise ético-moral na perspectiva da Laudato Si. Revista Iberoamericana de Bioética, Madrid?, n. 04, p. 01-12, 2017. Disponível em: https://revistas.comillas.edu/index.php/bioetica-revistaiberoamericana/article/view/7633/7668. Acesso em: 17 nov. 2020.

POTTER, V.R. Bioética global: construindo a partir do legado de Leopold. Tradução de Cecília Camargo Bartalotti. São Paulo: Loyola, 2018.

POTTER, V.R. Bioética: ponte para o futuro. Tradução de Diego Carlos Zanella. São Paulo: Loyola, 2016.

SCANNONE, J. C. A ética social do Papa Francisco: O Evangelho da misericórdia segundo o espirito de discernimento. Cadernos de Teologia Publica, São Leopoldo?, ano XV, v. 15, n. 135, p. 1-16, 2018. Disponível em: http://www.ihu.unisinos.br/images/stories/cadernos/teopublica/135cadernosteologia publica.pdf. Acesso em: 17 nov. 2020.

SGANZERLA, A. Leo Pessini: um bioeticista da esperança. Revista Iberoamericana de Bioética, Madrid?, n. 10, p. 1-7, 2019. Disponível em: https://revistas.comillas.edu/index.php/bioetica-revistaiberoamericana/article/view/11589/10855. Acesso em: 17 nov. 2020.

SGANZERla, A.; ZANELla, D. C. (orgs.). A bioética de V. R. Potter: 50 anos depois. Curitiba: PUCPRESS, 2020.

ZANELLA, D.C. Humanidades e ciência: uma leitura a partir da bioética de Van Rensselaer Potter. Interface - Comunicação, Saúde, Educação, São Paulo, v. 22, n. 65, p. 473-480, 2018. Disponível em: https://www.scielosp.org/article/icse/2018.v22n65/473-48o/pt/. Acesso em: 17 nov. 2020. 